\title{
Commentary
}

\section{The journey to education}

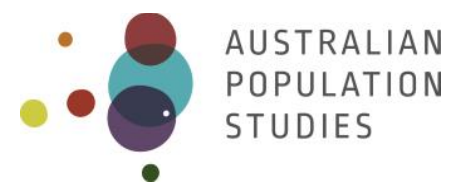

\section{Jonathan Corcoran* The University of Queensland}

Jim Cooper The University of Queensland

* Corresponding author. Email: ji.corcoran@uq.edu.au. Address: Queensland Centre for Population Research, School of Earth and Environmental Sciences, The University of Queensland, Brisbane, Australia 4072.

Paper received 6 March 2021; accepted 28 April 2021; published 31 May 2021

\section{Introduction}

The journey to work represents a daily reality for many Australians. This diurnal movement between usual residence and work raises important social, public health, economic and environmental concerns alongside significant challenges for government and transit providers to meet the various demands placed by the commute (Cervero 2004; Kanaroglou et al. 2015; Chatterjee et al. 2020). First introduced as a data product in the Australian Census of Population and Housing in $2001^{1}$, the census remains the principal source of data on the journey to work in Australia (Cooper and Corcoran 2018).

The Australian Bureau of Statistics (ABS) capture the journey to work via an individual's response to three separate questions; the location of usual residence; the location of their workplace alongside the reported method by which they commuted. When combined, these data enable users to examine patterns in the chosen mode(s) of travel, total commute distance travelled, sex, industry sector of occupation and how these vary by SA2 across the nation. Importantly, these data provide the necessary information to reveal how commuting differs between our cities and regions and to inform policies on sustainable transport initiatives (Black et al. 2002; Mees et al. 2008), highlight the extent of long distance (in some literature referred to as 'extreme') commuting (DeSilva et al. 2011), and help to guide how we might progress towards the 30 Minute City (Kelobonye et al. 2019, 2020).

Whilst the 2016 ABS Census reported a total of 9.2 million Australians journeying to work, there exists a multitude of daily journeys including that of the journey to education that remain uncaptured. These uncaptured journeys equally impose important social, economic, public health and environmental consequences that are common to the journey to work (McGuckin et al. 2005; Collins and Kearns 2010). In relation to the journey to education, studies have sought to estimate the burden the home to

\footnotetext{
${ }^{1}$ The questions on Place of Work have been asked since 1971, but the results have been available at small area level only recently. Prior to 2001, the study areas were limited to major urban areas in each state and territory. For the 2001 Census, Destination Zones were expanded to encompass the whole of Australia, including the territories of Jervis Bay, Cocos Keeling Islands and Christmas Island (but excluding the External Territories). In 1996 journey to work data were available only for those people who worked in the Detailed Study Areas in urban areas. Any journey to work who was enumerated in a study area but gave a workplace address that was outside this study area was coded as 'Worked Outside Study Area'. For example, if a person commuted from Mittagong to work in Sydney, journey to work data for that person could not be obtained.
} 
education trip places on the transport system (for example see, Lang et al. 2011) with one piece of work reporting that only around 25 percent of primary school children journey to school by active travel, with the remainder using public or private transport (Garrard 2016). The propensity to avoid active travel to journey to school has increased significantly since the 1970s, for a variety of reasons (Garrard 2016). Moreover, these uncaptured daily journeys (as is the case with the journey to education) frequently occur at the same time and use the same or similar infrastructure as the journey to work, adding to traffic congestion at peak times (Pooley et al. 2005) and requiring additional public transport capacity which potentially might be underutilised for the remainder of the day (Jara-Díaz et al. 2017).

We suggest that there exists an opportunity to impose a minor extension to the current ABS 2021 Census questions that would enable the capture of the journey to education alongside that of the journey to work which would permit analysis of this significant transport issue at a much more detailed geographic level than has been possible to date. The next section explores what this update to the Census could look like and seeks to explore how respondents are likely to understand such a question along with the potential inaccuracies in answers that it might introduce.

\section{Proposed addition to existing census questions}

The importance of understanding the characteristics, dynamics and drivers of the commute are well documented and statistical agencies around the world seek to collect such information as part of their regular census data collection (see for example, Office for National Statistics 2021; United States Census Bureau 2021; Statistics Canada 2021).

Here in Australia, policy debates such as the "30-minute city" demand information that include the data on the journey to work to better understand and track how the commute has responded to shift in urban form and transport infrastructure (Levinson 2019). The 30-minute city concept originates from the Greater Sydney Commission (the agency responsible for planning the Sydney region) which was concerned with improving connectivity for residents such that larger proportions of people are able to access their closest metropolitan and strategic centre using the public transport and/or walking within 30 minutes (Greater Sydney Commission 2021). Set alongside the rise in long distance commuting in Australia (Ye and Ma 2019), census data that capture our daily journeys are of growing importance as we seek to inform smart policy seeking to re-configure our cities and regions in a manner that is more sustainable, both socially and environmentally. We argue that an important component of daily travel currently absent from census data is that of the journey to education which is a much-needed supplement to that of the journey to work. Capturing both types of daily journey would provide valuable additional information that in turn is valuable input to ongoing policy debates including the 30-minute city. Furthermore, the addition of a journey to education question would also permit the development of a nationwide perspective on important public health questions, such the propensity for active travel, that when placed in the context of a household's travel dynamics could be employed to help explain the prevalence of active travel - a topic of rising national policy importance (Carver et al. 2019).

In the recent call by the ABS for submissions regarding the upcoming 2021 ABS Census, "transport" was the most common topic accounting for $18.7 \%$ of all suggestions (ABS 2018). Furthermore, the 
$A B S$ have begun to explore the feasibility of including a journey to education question as part of the 2021 Census topic evaluation process (ABS 2018). The ABS reports that their preliminary investigations of combining mode of travel alongside the name and address of educational institution raise a number of doubts around the additional burden this question would place on respondents to recall the address (of the education institution) alongside concerns of the complexity of responses. More specifically, the ABS points to the way in which both tertiary students that typically have irregular study schedules as well as school aged children being dropped off by parents as part of multi-destination trips would likely create complex responses (ABS 2018).

The proposal we put forward in this commentary seeks to address both how the current journey to work question alongside a new journey to education question might be recast. We suggest that the current burden and cost of coding the place of work or education could be significantly improved. The existing journey to work data enable the calculation of a distance travelled measure. However, we recognise that the coding of place of work to a location at a level of geography detailed enough to permit such a calculation is an onerous task, and to duplicate that task for a journey to education analysis would have significant financial and resourcing issues for the ABS. Accordingly, we suggest that a question about distance travelled be asked directly of respondents. The existing questions on education would act to focus attention on a specific education institution and a follow up question about distance should not be burdensome. This avoids the need to ask for the specific institution to be identified, with its address as well as removing the need for extensive response processing. While it would be extremely desirable to also ask about mode of travel, using a question very similar to that of the 2021 Census question 49 (How did the person get to work on Tuesday 10 August 2021? See the Appendix for the question and full set of response categories), we appreciate that doing so would increase both respondent burden and census processing costs beyond what could be realistically achieved in the current economic climate.

On the subject of census processing costs, we would suggest revisiting the need to code place of work to such a high degree of geographic accuracy as is currently done. Currently the ABS invests substantial time in geocoding the physical destination associated with the journey to work question wherein there is potential to revisit the way in which this is currently done. Alternatively, we suggest that a more cost-efficient approach would be to engage State/Territory transport departments and other relevant agencies who support this data collection to justify why individual destination zones continue to be required rather than the more cost and time efficient alternative of adopting a Statistical Area 1 level coding. We suggest that the cost savings this would generate could offset the additional resources required to add the question on journey to education which we propose.

Following Question 30 (of the upcoming 2021 census: What type of education institution is the person attending? See the Appendix for the question and full set of response categories), which asks what type of educational institution the person is attending (if the respondent did not answer NO to Question 29 of the 2021 census: Is the person attending a school or other education institution? See Appendix A for the question and full set of response categories) and allows for only one box to be ticked, a new question could then be asked taking the form of that outlined in Figure 1. We acknowledge that the pre-set distance ranges suggested in Figure 1 would require further testing and analysis to determine their suitability for most respondents. 


\begin{tabular}{|c|c|}
\hline $\begin{array}{l}\text { Whe } \\
\text { trav }\end{array}$ & $\begin{array}{l}\text { he persons physically travels to that institution } \\
\text { oget there? }\end{array}$ \\
\hline Pre- & tresponses could be in distance ranges such as: \\
\hline 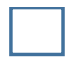 & Does not physically travel to that institution \\
\hline 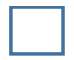 & Travels less than 1 kilometre \\
\hline $\mathbf{S}$ & Travels between 1 kilometre and 5 kilometres \\
\hline 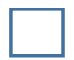 & Travels between 5 kilometres and 10 kilometres \\
\hline 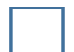 & Travels more than 10 kilometres \\
\hline
\end{tabular}

Figure 1: Proposed 2026 census question capturing the journey to education Source: authors

By asking a general question of the form indicated in Figure 1 regarding typical distance travelled, we would avoid the issues of recall that were a concern in testing a travel to education question for the 2021 Census (ABS 2018). Likewise, we are not advocating a question about mode of travel to education, for similar reasons as well as processing cost. A question of the type indicated above with standardised reporting categories should be seen merely as an exploratory step to addressing the need for data about how far people travel to education. It would provide hitherto unavailable data on the extent of such travel at national, State and local level, revealing clearly for the first time the cost, time and infrastructure burden these journeys generate. Issues of how often and by what means students travel are still of great importance, but perhaps are best left to future consideration.

\section{Discussion and conclusion}

Given that the journey to education often aligns in terms of timing (twice daily: in the morning and afternoon coinciding with 'peak hour') with the journey to work, gathering additional information about the daily peak travel periods is important to better understanding traffic flows and transport patterns across cities and regions. This has important planning implications for both private and public transport infrastructure. The Queensland Government spends in the vicinity of \$200 million annually to subsidise bus travel for school students, mainly for those who travel to a school outside their local area, involving the daily use of approximately 2,000 buses in Queensland (Department of Transport and Main Roads 2019).

One of the principal barriers to active travel to school in Australia frequently cited is the distance involved, although in many Asian countries children walk much farther than those in Australia (Garrard 2016). Improved planning targeted at the reduction of distance may encourage more active travel among school age children (Garrard 2016), however developing such place-based policies is contingent on high quality data. Our proposed additional census question presented in this commentary offers one avenue to meet this data deficiency and provide country-wide information on the journey to education.

Acknowledging that a journey to education question has to date tested unsuccessfully by the ABS, we suggest re-visiting the way in which this question is posed (adopting our proposed solution presented here) along with the potential for an offsetting cost saving in the data coding process if Place of Work is coded to SA1 rather than destination zone. In sum, we hope that this commentary piece lays out 
both a convincing argument alongside a feasible new question such that the ABS re-considers the inclusion of journey to education in the 2026 Census. More broadly, the inclusion of a journey to education question within the Australian census has the potential to raise awareness of its importance and highlight a viable pathway for its inclusion in other national census data collections.

\section{References}

ABS (2018) Census of Population and Housing: Topic Directions, 2021 Catalogue No. 2007.0.55.001. Canberra: ABS https://www.abs.gov.au/ausstats/abs@.nsf/Lookup/by\%20Subject/2007.0.55.001 2021 Main\% 20Features $\sim$ Topic\%20directions $\sim 6$. Accessed on 6 February 2021.

Black J A, Paez A, and Suthanaya P A (2002) Sustainable urban transportation: performance indicators and some analytical approaches. Journal of Urban Planning and Development 128(4): 184-209. https://doi.org/10.1061/(ASCE)0733-9488(2002)128:4(184)

Carver A, Barr A, Singh A, Badland H, Mavoa S, and Bentley R (2019) How are the built environment and household travel characteristics associated with children's active transport in Melbourne, Australia? Journal of Transport and Health 12: 115-129. https://doi.org/10.1016/i.jth.2019.01.003

Cervero R (2004) Transit-oriented Development in the United States: Experiences, Challenges, and Prospects (Vol. 102). Transportation Research Board. Washington DC. USA. http://www.trb.org/Publications/Blurbs/154989.aspx

Chatterjee K, Chng S, Clark B, Davis A, De Vos J, Ettema D, Handy S, Martin A and Reardon L (2020) Commuting and wellbeing: a critical overview of the literature with implications for policy and future research. Transport Reviews 40(1): 5-34. https://doi.org/10.1080/01441647.2019.1649317

Collins D and Kearns R A (2010) Walking school buses in the Auckland region: A longitudinal assessment. Transport Policy 17(1): 1-8. https://doi.org/10.1016/j.tranpol.2009.06.003

Cooper J and Corcoran J (2018) Journey to work in Australia Catalogue No. 2071.0.55.001. Canberra: ABS https://www.abs.gov.au/ausstats/abs@.nsf/mf/2071.0.55.001. Accessed on 6 February 2021.

De Silva H, Johnson L and Wade K (2011) Long distance commuters in Australia: a socio-economic and demographic profile. Proceeding of the $34^{\text {th }}$ Australasian Transport Research Forum. September, 2011. https://www.bitre.gov.au/publications/2011/sp 005

Garrard J (2016) Walking, riding or driving to school: What influences parents' decision making. South Australia Department of Planning, Transport and Infrastructure. South Australia Government. https://dpti.sa.gov.au/ data/assets/pdf file/0004/513508/Walking riding or driving to schoo l- what influences parents decision making-Literature Review .pdf. Accessed on 18 May 2021.

Greater Sydney Commission (2021) Greater Sydney Commission. Sydney. https://www.greater.sydney/pi2-30-minute-city. Accessed on 18 May 2021.

Jara-Díaz S, Fielbaum A and Gschwender A (2017) Optimal fleet size, frequencies and vehicle capacities considering peak and off-peak periods in public transport. Transportation Research Part A: Policy and Practice 106: 65-74. https://doi.org/10.1016/j.tra.2017.09.005

Kanaroglou P S, Higgins C D and Chowdhury T A (2015) Excess commuting: a critical review and comparative analysis of concepts, indices, and policy implications. Journal of Transport Geography 44: 13-23. https://doi.org/10.1016/j.jtrangeo.2015.02.009

Kelobonye K, McCarney G, Xia J C, Swapan M S H, Mao F and Zhou H (2019) Relative accessibility analysis for key land uses: A spatial equity perspective. Journal of Transport Geography 75: 82-93. https://doi.org/10.1016/j.jtrangeo.2019.01.015

Kelobonye K, Zhou H, McCarney G and Xia J C (2020) Measuring the accessibility and spatial equity of urban services under competition using the cumulative opportunities measure. Journal of Transport Geography 85: 102706. https://doi.org/10.1016/i.jtrangeo.2020.102706 
Lang D, Collins D and Kearns R (2011) Understanding modal choice for the trip to school. Journal of Transport Geography 19(4): 509-514. https://doi.org/10.1016/i.jtrangeo.2010.05.005

Levinson D M (2019) The 30-minute city: Designing for access. Network Design Lab. https://ses.library.usyd.edu.au/handle/2123/21630. Accessed on 18 May 2021.

Mees P, O'Connell G and Stone J (2008) Travel to work in Australian capital cities, 1976-2006. Urban Policy and Research 26(3): 363-378. https://doi.org/10.1080/08111140802311236

McGuckin N and Srinivasan N (2005) The journey-to-work in the context of daily travel. In Census Data for Transportation Planning Conference. May 2005. http://download.ctpp.transportation.org/Future/resource papers/Journey-to-Work.pdf. Accessed on 18 May 2021.

Office for National Statistics (2021) Office for National Statistics. United Kingdom: ONS. https://www.ons.gov.uk/census. Accessed on 18 May 2021.

Pooley C G, Turnbull J and Adams M (2005) The journey to school in Britain since the 1940s: continuity and change. Area 37(1): 43-53. https://doi.org/10.1111/j.1475-4762.2005.00605.x

Queensland Department of Transport and Main Roads (2019) Annual Report 2018-2019-Transport and Main Roads. Queensland Government. https://www.publications.qld.gov.au/dataset/annualreport-2018-2019-transport-and-main-roads. Accessed on 18 May 2021.

Statistics Canada (2021) Statistics Canada. Canada. https://www.statcan.gc.ca/eng/start. Accessed on 18 May 2021.

United States Census Bureau (2021) United States Census Bureau. United States. https://www.census.gov/. Accessed on 18 May 2021.

Ye R and Ma L (2019) Australian city workers' average commute has blown out to 66 minutes a day. How does yours compare? The Conversation. July 30, 2019. https://theconversation.com/australiancity-workers-average-commute-has-blown-out-to-66-minutes-a-day-how-does-yours-compare120598. Accessed on 18 May 2021. 


\section{Appendix}

2021 Census Questions and response categories

\begin{tabular}{|c|c|}
\hline $\begin{array}{l}\text { 29. Is the person attending a school or } \\
\text { other education institution? } \\
\text { - Include preschool, online, external or } \\
\text { correspondence study. }\end{array}$ & $\begin{array}{l}\text { o No Go to } 31 \\
\text { o Yes, full-time student } \\
\text { o Yes, part-time student }\end{array}$ \\
\hline
\end{tabular}

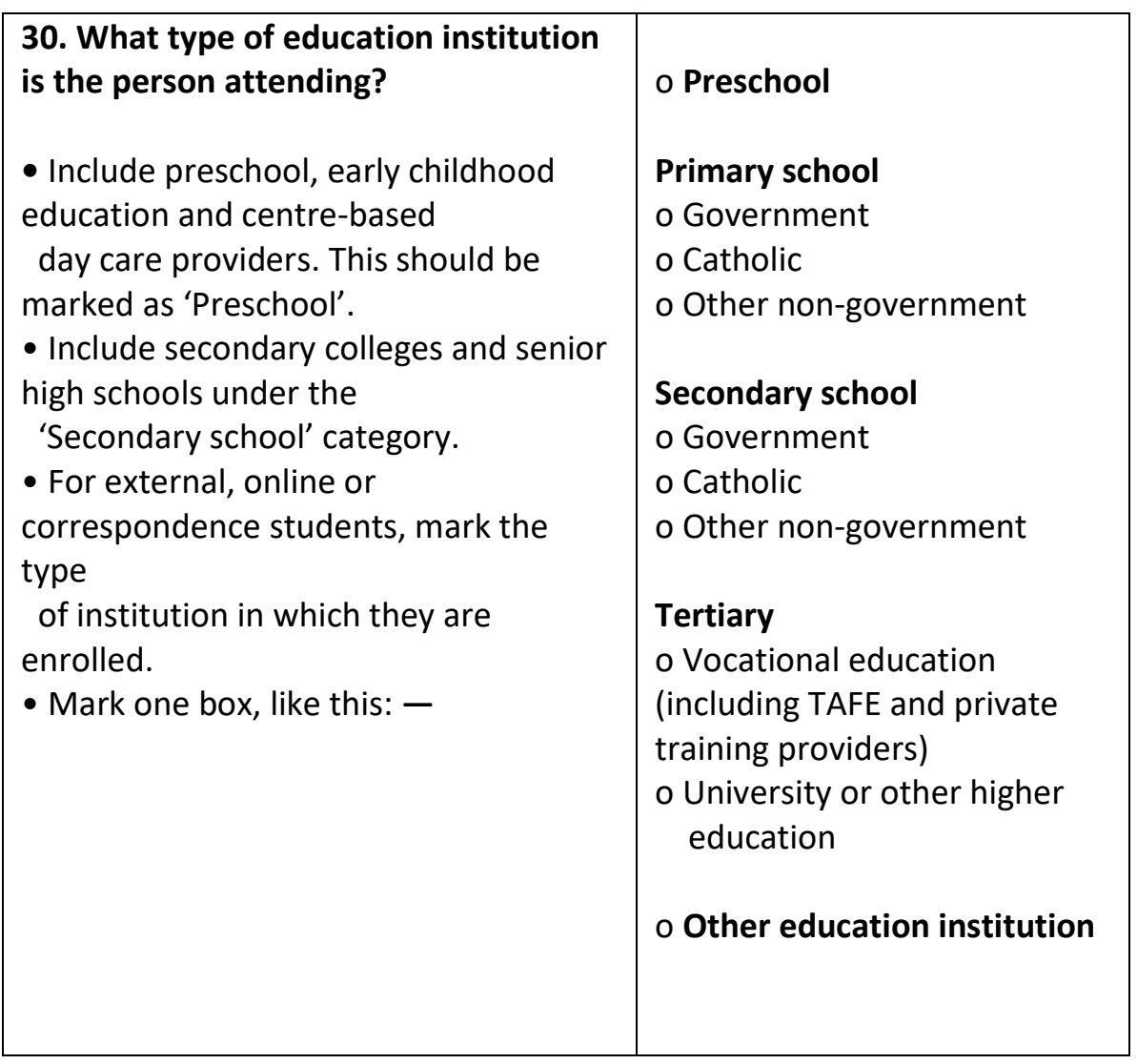




\begin{tabular}{|c|c|}
\hline $\begin{array}{l}\text { 49. How did the person get to work on } \\
\text { Tuesday } 10 \text { August } 2021 \text { ? } \\
\text { If the person used more than one } \\
\text { method of travel to work, mark all that } \\
\text { apply, like this: - }\end{array}$ & $\begin{array}{l}\text { o Train } \\
\text { o Bus } \\
\text { o Ferry } \\
\text { o Tram (including light rail) } \\
\text { o Taxi or ride-share service } \\
\text { o Car - as a driver } \\
\text { o Car - as a passenger } \\
\text { o Truck } \\
\text { o Motorbike or motor scooter } \\
\text { o Bicycle } \\
\text { o Walked only } \\
\text { o Other } \\
\text { o Worked at home } \\
\text { o Did not go to work }\end{array}$ \\
\hline
\end{tabular}

